\title{
Survival of adult reddish egrets Egretta rufescens marked with satellite transmitters
}

\author{
Lianne M. Koczur ${ }^{1, *}$, Bart M. Ballard ${ }^{1}$, M. Clay Green ${ }^{2}$ \\ ${ }^{1}$ Caesar Kleberg Wildlife Research Institute, Texas A\&M University-Kingsville, Kingsville, Texas 78363, USA \\ ${ }^{2}$ Department of Biology, Texas State University, San Marcos, Texas 78666, USA
}

\begin{abstract}
The reddish egret Egretta rufescens is the rarest heron in North America, and there are many information gaps in our understanding of its ecology. The population size of the reddish egret is relatively small, and although its range spans from the Gulf Coast of the United States to the northern coast of South America, it is restricted to shallow, coastal lagoon systems. Nest survival and juvenile survival have been examined in the reddish egret; however, adult survival has not. We marked 30 adult reddish egrets with satellite transmitters and used the known-fate model in Program MARK to estimate monthly survival. Monthly survival estimates were high and best explained by season, with a 0.992 (95\% CI: 0.974-0.997) survival rate during the breeding season and 0.949 (95\% CI: 0.912-0.971) during the nonbreeding season. This is the first study to estimate adult survival of reddish egrets, and it provides new information on the ecology of the species.
\end{abstract}

KEY WORDS: Egretta rufescens $\cdot$ Reddish egret $\cdot$ Survival

\section{INTRODUCTION}

The reddish egret Egretta rufescens is thought to be a relatively long-lived waterbird that exhibits delayed sexual maturity. Although their range extends from the southern United States to northern South America, they are restricted to shallow, coastal lagoons throughout the annual cycle. Furthermore, the population declined prior to the passing of the Migratory Bird Treaty Act and has remained relatively low, with an estimated global population of 5000 to 11300 mature individuals (Wilson et al. 2014, BirdLife International 2016). The population of reddish egrets is estimated at 2000 mature individuals in Texas, USA, where the largest known breeding colony occurs (Wilson et al. 2014). Consequently, the reddish egret is listed as Near Threatened by the International Union for the Conservation of Nature (BirdLife International 2016). It is also state listed as

\footnotetext{
*Corresponding author: liannekoczur@gmail.com
}

threatened in Texas and a species of conservation concern throughout much of its range. One of the main goals of the Reddish Egret Working Group is to identify threats to reddish egrets throughout their range and to determine factors that may be limiting population growth (Wilson et al. 2014).

Despite the status of this species, reddish egrets have not been well studied. Two studies have examined juvenile survival (Bates et al. 2015, Geary et al. 2015), yet there are no estimates of adult survival. Adult survival is a particularly important vital rate in contributing to population growth of long-lived species (Saether \& Bakke 2000). Estimates of adult survival rates are essential in obtaining a holistic understanding of reddish egret ecology and population dynamics. Estimating survival on a seasonal scale can be beneficial in understanding periods in the annual cycle that may be limiting population growth. Furthermore, reddish egrets breeding in Texas

๑ T The authors 2017. Open Access under Creative Commons by Attribution Licence. Use, distribution and reproduction are unrestricted. Authors and original publication must be credited. 
exhibit a partial migration strategy (Koczur 2017), allowing a unique opportunity to examine how migratory behavior may influence adult survival. Baseline data on survival can be used to assess and compare survival rates in other portions of the species' range and to provide a basis for future estimates. The objective of this study was to estimate survival rates of adult reddish egrets that breed in Texas.

\section{MATERIALS AND METHODS}

Reddish egrets were trapped at 9 colonies in the Laguna Madre of Texas during the breeding seasons of 2010-2012 and 2014. Egrets were trapped using a modified noose mat placed near the nest. Once captured, we recorded morphometric data and affixed a US Geological Survey (USGS) aluminum band on the left tarsus and a plastic alphanumeric colored band on the right tarsus. We outfitted egrets with $22 \mathrm{~g}$ solar powered satellite transmitters (PTT-100, MicrowaveTelemetry) as a backpack harness using Teflon ribbon. Transmitters were $<3.24 \%$ of body mass. The transmitters were programmed to record 6 locations per day, and the locations were accurate to $\pm 18 \mathrm{~m}$. We collected blood samples in 2014 to determine sex of the individuals, and also collected 7 carcasses of egrets that died during the study. We used DNA extracted from blood of the live egrets, and from footpad skin, feathers and bones of carcasses to determine sex (Fridolfsson \& Ellegren 1999, Wang et al. 2011). We then used a discriminate analysis to determine sex of the remaining 15 egrets (Koczur et al. 2015).

Monthly survival was estimated from 1 June 2010 through 1 August 2016. We were able to differentiate between a mortality and transmitter failure based on a combination of GPS locations and diagnostic information on device batteries from the Argos website. Mortality was assumed when GPS locations occurred in the exact location (i.e. within $18 \mathrm{~m}$ ) for $>1 \mathrm{~d}$, and transmitter failure was assumed when the transmitter began to miss locations or exhibit unusual voltage readings in the diagnostic information prior to signal loss. In instances where the transmitter failed, the birds were censored rather than recorded as dead. We used the known-fate platform in Program MARK (White \& Burnham 1999) to estimate survival. The assumptions of known-fate models include: (1) marking an individual does not affect its fate, (2) the fates of marked individuals are independent, and (3) censoring is not related to mortality. Several individuals were tracked for multiple years, including several that migrated. Furthermore, all egrets tracked remained in habitat considered normal for the species, and those that were tracked for $>1$ breeding season appeared to exhibit normal breeding behavior (Koczur 2017). Therefore, we assumed marking had no measurable effect on survival. Both members of one nesting pair were marked; however, after breeding ceased the individuals did not remain together, and we assumed their fates to be independent.

We included sex, migratory status, and season as covariates to assess variation in survival. Color morph was also assessed as a covariate in preliminary analyses; however, it received low model support and was excluded from the final analysis. We used 2 variations of season: (1) we classified seasons into breeding (March-September) and nonbreeding (October-February; 2-Season); and (2) we classified seasons into breeding (May-September), postbreeding/autumn migration (October-November), nonbreeding (December-February), and pre-breeding/spring migration (March-April; 4-Season). We evaluated 11 candidate models as to their ability to explain variation in monthly survival of reddish egrets. Annual survival was estimated by calculating the product of the survival estimates from the top model, and the delta method (Seber 1982, Powell 2007) was used to calculate the variance.

\section{RESULTS}

Sixteen of the reddish egrets were female (12 dark morphs and 4 white morphs), 14 were male ( 7 dark morphs and 7 white morphs), and 6 of the egrets ( 2 females and 4 males) migrated long distances $(\sim 1200 \mathrm{~km})$ out of the Laguna Madre during winter (Koczur 2017). We did not detect differences in mortality rates between residents and migrants; $41 \%$ of resident and $50 \%$ of migrant egrets died during the study period; however, the sample size of migrants was small. Eleven of 15 known mortalities occurred in Texas; 9 of those occurred during the nonbreeding period between November and February, and 2 were in June. Another died just across the border in Mexico in December, and the remaining 3 also died during the nonbreeding period in Mexico. Seven of the egrets that died were female and 8 were male. Seven transmitters were recovered on islands and tidal flats; however, we were not able to determine the causes of mortality with certainty. Eleven egrets were censored because of transmitter battery failure, and 4 egrets were still alive at the end of this study (August 2016). 
Monthly survival estimates for adult reddish egrets were high. The number of observation months for analysis was 591 . There were 5 competing models (change in Akaike's information criterion adjusted for small sample size, $\Delta \mathrm{AIC}_{\mathrm{c}}<3$ ), which accounted for $86 \%$ of the model weight (Table 1). The top model indicated that monthly survival was best explained by 2-Season, with monthly survival estimated at 0.992 (SE: 0.004, 95\% CI: 0.974-0.997) during the breeding season and 0.949 (SE: 0.014, 95\% CI: 0.912-0.971) during the nonbreeding season. The second best model was 4-Season; monthly survival was estimated at 0.993 (SE: $0.004,95 \%$ CI: $0.972-$ 0.0998 ) during the breeding season, 0.972 (SE: 0.016, $95 \%$ CI: 0.916-0.991) during post-breeding/autumn migration, 0.929 (SE: 0.022, 95\% CI: 0.870-0.963) during winter, and 0.986 (SE: 0.013, 95\% CI: 0.9090.998) during pre-breeding/spring migration. Season (both derivations) was an important parameter as it occurred in the 7 top models that accounted for $99 \%$ of the weight. Sex and Migratory Status did not appear to be important in explaining variation in survival of adult reddish egrets, as adding them to Season did not improve their explanatory power (Table 1). Annual survival was 0.756 (SE: 0.060).

\section{DISCUSSION}

The survival estimates of adult reddish egrets were relatively high and were similar to those found in other heron species. Estimates of annual survival of adult great blue herons Ardea herodias ranged from 73-78\% (life tables; see Vennesland \& Butler 2011), great egret $A$. alba adult survival was $74 \%$ (life

Table 1. Model results of monthly survival estimates for adult reddish egrets marked with satellite transmitters during 2010-2016, showing Akaike's information criterion adjusted for small sample size $\left(\mathrm{AIC}_{\mathrm{c}}\right)$, difference in $\mathrm{AIC}_{\mathrm{C}}$ values between the top model and other models $\left(\Delta \mathrm{AIC} \mathrm{C}_{\mathrm{c}}\right)$, model weight $\left(W_{i}\right)$, number of parameters $(K)$, and deviance

\begin{tabular}{|lccccc|}
\hline Model & $\mathrm{AIC}_{\mathrm{c}}$ & $\Delta \mathrm{AIC}_{\mathrm{c}}$ & $W_{i}$ & $K$ & Deviance \\
\hline 2-Season & 133.42 & 0.00 & 0.35 & 2 & 82.44 \\
4-Season & 134.93 & 1.51 & 0.17 & 4 & 79.90 \\
2-Season $\times$ Migratory Status & 135.06 & 1.64 & 0.15 & 6 & 75.96 \\
2-Season $\times$ Sex & 135.75 & 2.33 & 0.11 & 4 & 80.72 \\
2-Season $\times$ Migratory Status & 136.28 & 2.86 & 0.08 & 4 & 81.25 \\
4-Season $\times$ Sex & 136.81 & 3.39 & 0.06 & 8 & 73.60 \\
4-Season $\times$ Migratory Status & 137.06 & 3.63 & 0.06 & 8 & 73.85 \\
Constant & 141.84 & 8.41 & 0.01 & 1 & 92.87 \\
Sex & 142.86 & 9.44 & 0.00 & 2 & 91.88 \\
Migratory status & 143.19 & 9.76 & 0.00 & 2 & 92.21 \\
Migratory status $\times$ Sex & 144.35 & 10.93 & 0.00 & 4 & 89.32 \\
\hline
\end{tabular}

tables; Kahl 1963), and little egret Egretta garzetta adult survival was estimated at $78 \%$ (capture-recapture; Galarza \& Arizaga 2014). In long-lived species, survival is generally low in the juvenile stage and increases in adulthood (Bennetts et al. 1999, Oppel \& Powell 2010, Sergio et al. 2011), which was documented in each of the species mentioned previously. Bates et al. (2015) estimated juvenile survival of reddish egrets at $78 \%$ for the first 6 mo after hatch. Geary et al. (2015) found similar results for the first 6 mo after hatch at $83 \%$; yet survival decreased to $53 \%$ by 17 mo after hatch.

Our top model indicated that survival was lower in the nonbreeding season compared to the breeding season. Recent research on this cohort of reddish egrets marked with satellite transmitters found that they exhibited a partial migration strategy, with $40 \%$ of the marked individuals migrating out of the Laguna Madre during winter months (Koczur 2017). A previous study on the spatial and temporal availability of reddish egret foraging habitat found available habitat to decrease during winter months because of changes in water level during that time (Bates et al. 2016). Reddish egrets require shallow water $(<20 \mathrm{~cm})$ for foraging, and winter weather conditions that lead to fluctuations in water levels reduce the amount of available shallow water habitat. Departure of the egrets from the Laguna Madre corresponded to the time when available habitat began to decline. Spatial and temporal fluctuations in water level and the availability of foraging habitat is common in wetlands due to seasonal variation in rainfall and tide levels (Arengo \& Baldassarre 1999). Furthermore, cold weather can influence prey movement and availability (Frederick \& Loftus 1993, Pattillo et al. 1997) and foraging behavior (DuBowy 1996). Migration is energetically expensive and can influence survival; however, if an individual cannot survive or meet its requirements in the breeding area, it must migrate to a suitable area. Despite the inherent risks of migration, we were not able to detect differences in mortality rates of resident and migrant egrets during the study period. A larger sample size of both residents and migrants would improve our confidence in these results.

Survival rates have been found to be lower in the nonbreeding season in migratory red knots Calidris canutus canutus (Leyrer et al. 2013). The 
authors suggested that intraspecific competition and physiological stress at wintering sites may have influenced survival. Severe winter weather reduced survival in resident and migratory Eurasian oystercatchers Haematopus ostralegus (Duriez et al. 2012). Low survival due to carry-over effects from conditions at winter sites have also been found in the migratory burrowing owl Athene cunicularia (Wellicome et al. 2014). This study did not examine the influence of competition or weather on survival during the nonbreeding period. If foraging habitat decreases during winter for resident reddish egrets, competition may be an important consideration when assessing body condition and survival in this species.

There are no documented causes of mortality in adult reddish egrets. Coyotes Canis latrans are present in the Laguna Madre and are a known predator of waterbird nests and, potentially, of young birds. Although they are not believed to be a significant source of mortality in adults, 2 of the carcasses appeared to have been the result of coyote depredation or scavenged post-mortem by coyotes. Another potential predator present in the region is the peregrine falcon Falco peregrinus. Peregrines have been documented preying on gulls, shorebirds, and waterfowl (Oro 1996). While depredation by these species may occur, it is unlikely that they pose significant threats to the survival of adult reddish egrets; predators are believed to be more of a threat to eggs and flightless young (Wilson et al. 2014).

Senescence is another possible cause of mortality. There are longevity reports for many species of heron (Clapp et al. 1982): little blue herons at 13 yr $11 \mathrm{mo}$, tricolored herons at $17 \mathrm{yr} 8 \mathrm{mo}$, black-crowned night heron at $21 \mathrm{yr} 1 \mathrm{mo}$, snowy egret Egretta thula at $11 \mathrm{yr}$ $3 \mathrm{mo}$; however, the lifespans of these species are not well known. The age at first breeding is assumed to be 2-3 yr for reddish egrets. We were unable to determine the age of reddish egrets in this study and therefore only knew they were $\geq 2 \mathrm{yr}$ of age. Several egrets in this study transmitted data for $3-4$ yr. If these adults were captured at an older age, it is reasonable to assume they could have died from natural causes. Lastly, we did not observe measureable effects in survival due to transmitters; however, these devices have been found to negatively impact behavioral and ecological traits in various avian species (Barron et al. 2010). Observational studies of unmarked and marked egrets would be beneficial for determining transmitter effects.

This is the first estimate of adult survival in the reddish egret and provides important information on the ecology of the species, which can be used to direct conservation strategies. Much emphasis is placed on the protection and management of colonial nesting islands, which is critical to reproductive success. However, the winter period appears to limit survival of juvenile reddish egrets (Geary et al. 2015) and also appears to be the period when most adult mortality occurs. This study included only reddish egrets that were breeding in Texas; future research should examine adult and juvenile survival rates in other portions of the species' range. The results of this study can also be used as baseline estimates to assess survival rates of reddish egrets in the future.

Acknowledgments. Funding for this project was provided by the Walter Fondren III Fellowship in Shorebird and Wading Bird Research at the Caesar Kleberg Wildlife Research Institute and USFWS Region 4 Migratory Bird Program. We thank D. Wester for assistance with statistical analyses. Thanks to A. Fedynich and D. Williford for reviewing this manuscript. Trapping and banding were conducted under TAMUK IACUC \#2013-05-23, IACUC \#2010-03-24A, and USGS bird banding permit \#21314. This is manuscript \#17-112 of the Caesar Kleberg Wildlife Research Institute.

\section{LITERATURE CITED}

Arengo F, Baldassarre GA (1999) Resource variability and conservation of American flamingos in coastal wetlands of Yucatán, Mexico. J Wildl Manag 63:1201-1212

* Barron DG, Brawn JD, Weatherhead PJ (2010) Meta-analysis of transmitter effects on avian behaviour and ecology. Methods Ecol Evol 1:180-187

Bates EM, Koczur LM, Ballard BM (2015) Post-fledging survival and dispersal of juvenile reddish egrets (Egretta rufescens). Waterbirds 38:401-406

Bates EM, Koczur LM, Krainyk A, Ballard BM, Kasner AC (2016) Spatial and temporal dynamics of foraging habitat availability for reddish egrets in the Laguna Madre, Texas. Int J Biodivers Conserv 8:251-258

* Bennetts RE, Dreitz VJ, Kitchens WM, Hines JE, Nichols JD (1999) Annual survival of snail kites in Florida: radio telemetry versus capture-resighting data. Auk 116: 435-447

BirdLife International (2016) Egretta rufescens. The IUCN Red List of Threatened Species 2016:e.T22696916A935 92693. http://dx.doi.org/10.2305/IUCN.UK.2016-3.RLTS. T22696916A93592693.en (accessed 13 January 2017)

Clapp RB, Klimkiewicz MK, Kennard JH (1982) Longevity records of North American birds: Gaviidae through Alcidae. J Field Ornithol 53:81-208

DuBowy PJ (1996) Effects of water level and weather on wintering herons and egrets. Southwest Nat 41:341-347

* Duriez O, Ens BJ, Choquet R, Pradel R, Klaassen M (2012) Comparing the seasonal survival of resident and migratory oystercatchers: carry-over effects of habitat quality and weather conditions. Oikos 121:862-873

Frederick PC, Loftus WF (1993) Responses of marsh fishes and breeding wading birds to low temperatures: a possible behavioral link between predator and prey. Estuaries $16: 216-222$ 
Fridolfsson A, Ellegren H (1999) A simple and universal method for molecular sexing of non-ratite birds. J Avian Biol 30:116-121

Galarza A, Arizaga J (2014) Population dynamics of a colony of little egrets Egretta garzetta at an estuary in northern Spain. Ardeola 61:285-296

Geary B, Green MC, Ballard BM (2015) Movements and survival of juvenile reddish egrets Egretta rufescens on the Gulf of Mexico coast. Endang Species Res 28: 123-133

Kahl PM (1963) Mortality of common egrets and other herons. Auk 80:295-300

Koczur LM (2017) Movement ecology of reddish egrets. $\mathrm{PhD}$ dissertation, Texas A\&M University-Kingsville, Kingsville, TX

Koczur LM, Kent GM, Geary B, Ballard BM, Meyer KD, Green MC (2015) Measurements of adult and hatch-year reddish egrets (Egretta rufescens). Waterbirds 38: 308-311

Leyrer J, Lok T, Brugge M, Spaans B, Sandercock BK, Piersma T (2013) Mortality within the annual cycle: seasonal survival patterns in Afro-Siberian red knots Calidris canutus canutus. J Ornithol 154:933-943

Oppel S, Powell AN (2010) Age-specific survival estimates of king eiders derived from satellite telemetry. Condor 112:323-330

* Oro D (1996) Are migrating peregrine falcons Falco peregrinus a threat to breeding Audouin's gull Larus audouinii at the Ebro Delta? Colon Waterbirds 19:270-272

Pattillo ME, Czapla TE, Nelson DM, Monaco ME (1997) Distribution and abundance of fishes and invertebrates in Gulf of Mexico estuaries, Vol II. Species life history summaries. ELMR Rep. No. 11. NOAA/NOS Strategic Envi-

Editorial responsibility: Michael Reed,

Medford, Massachusetts, USA ronmental Assessments Division, Silver Spring, MD

*Powell LA (2007) Approximating variance of demographic parameters using the delta method: a reference for avian biologists. Condor 109:949-954

Saether B, Bakke $\varnothing$ (2000) Avian life history variation and contribution of demographic traits to the population growth rate. Ecology 81:642-653

Seber GAF (1982) The estimation of animal abundance and related parameters, 2nd edn. Chapman, London

Sergio F, Tavecchia G, Blas J, López L, Tanferna A, Hiraldo F (2011) Variation in age-structured vital rates of a longlived raptor: implications for population growth. Basic Appl Ecol 12:107-115

Vennesland RG, Butler RW (2011) Great blue heron (Ardea herodias). In: Rodewald PG (ed) The birds of North America. Cornell Lab of Ornithology, Ithaca, NY. https://birdsna.org/Species-Account/bna/species/ grbher3 (accessed online 6 February 2017)

Wang Z, Zhou X, Lin Q, Fang W, Chen X (2011) New primers for sex identification in the Chinese egret and other ardeid species. Mol Ecol Resour 11:176-179

Wellicome TI, Fisher RJ, Poulin RG, Todd LD and others (2014) Apparent survival of adult burrowing owls that breed in Canada is influenced by weather during migration and on their wintering grounds. Condor 116: $446-458$

White GC, Burnham KP (1999) Program MARK: survival estimation from populations of marked animals. Bird Study 46(Suppl 1):120-138

Wilson TE, Wheeler J, Green MC, Palacios E (eds) (2014) Reddish egret conservation action plan. Reddish Egret Conservation Planning Workshop, October 2012, Corpus Christi, TX

Submitted: February 27, 2017; Accepted: June 2, 2017 Proofs received from author(s): July 7, 2017 